\title{
Comparison of neck length, relative neck length and height with incidence of cervical spondylosis
}

\author{
Syeda Bushra Ahmed ${ }^{1}$, Aisha Qamar', \\ Muhammad Imram³, Muhammad Faisal Fahim ${ }^{4}$
}

\begin{abstract}
Objective: To compare the neck length, relative neck length and height between patients with cervical spondylosis and healthy subjects.

Methods: This case control study was conducted at Patel hospital, Karachi after the ethical approval of Bahria University Medical and Dental College (BUMDC) and Patel hospital from September 2018 - February 2019. It enrolled eighty eight cases of cervical spondylosis and eighty eight healthy subjects. Radiographs were taken in the lateral view and neck length was measured as the distance from external occipital protuberance to seventh cervical vertebra spinous process. Then relative neck length was measured by dividing the neck length with height and multiplying it by 100 . The Kellgren Lawrence grade scale was used to assess the severity of cervical spondylosis.

Results: A total of 176 participants were analyzed. It was found that the height remains the significant determinant. The comparison of cases with control group was done using independent T-test which showed that the cases were significantly shorter than controls with a $\mathrm{p}$-value $<0.05$. The other variables such as neck length, and relative neck length were insignificant.

Conclusion: Short height can be considered as a risk factor for cervical spondylosis. Short-statured individuals should be counseled to adopt measures for the prevention of cervical spondylosis.
\end{abstract}

KEYWORDS: Cervical spondylosis, Height, Kellgren Lawrence grade scale, Radiography, Neck length, Relative neck length.

doi: https://doi.org/10.12669/pjms.36.2.832

How to cite this:

Ahmed SB, Qamar A, Imram M, Fahim MF. Comparison of neck length, relative neck length and height with incidence of cervical spondylosis. Pak J Med Sci. 2020;36(2):219-223. doi: https://doi.org/10.12669/pjms.36.2.832

This is an Open Access article distributed under the terms of the Creative Commons Attribution License (http://creativecommons.org/licenses/by/3.0), which permits unrestricted use, distribution, and reproduction in any medium, provided the original work is properly cited.

1. Dr. Syeda Bushra Ahmed, MBBS, M.Phil Scholar Anatomy.

2. Prof. Dr. Aisha Qamar, MBBS, M.Phil Anatomy.

Department of Anatomy,

3. Dr. Muhammad Imran, MBBS, FCPS

HOD Department of Radiology,

Patel Hospital,

Karachi, Pakistan.

4. Muhammad Faisal Fahim, M.Sc (Statistics), Researcher and Consultant Statistician,

2,4: Bahria University Medical and Dental College, DHA Phase-II,

Karachi, Pakistan.

Correspondence

Dr. Syeda Bushra Ahmed, MBBS.

M.Phil Scholar Anatomy,

Bahria University Medical and Dental College,

DHA Phase-II,

Karachi, Pakistan.

Email: sbushra.ahmed@hotmail.com

* Received for Publication:

April 3, 2019

* Revision Received:

October 17, 2019

* Revision Accepted:

October 23, 2019

\section{INTRODUCTION}

Worldwide, spinal diseases are the most common disorders affecting the cervical and lumbar spine. They are the degenerative changes occurring in relation with age, gender, occupation and lifestyle. The neck pain is one of the most frequent presenting complaints caused by uneven distribution of mechanical load at spine. ${ }^{1}$

Cervical spondylosis is defined as "the osteoarthritic degeneration of cervical spine components such as uncovertebral, facet joints and intervertebral discs causing sensory and motor dysfunctions". The pathogenesis of cervical spondylosis involves the formation of osteophytes, disc herniation, and hypertrophy of ligaments. ${ }^{2}$

Many factors are responsible for causing cervical spondylosis such as forward head posture, ${ }^{3,4}$ neck 
strain, stress, depression, sports, and occupational activities. Symptoms include pain in the neck and arms as well as numbness in the arms and fingers. The prevalence of neck pain is around $23.1 \%$ and incidence peaks up about $21.3 \%$ in the high-risk population of office and computer workers. ${ }^{5}$

It is most common in people aged over 55 years. It is also getting prevalent in young generation which is a major health concern. Some atypical manifestations have also been reported which include insomnia, headache, vertigo, nausea, abdominal discomfort, palpitation, amnesia, blurred vision, and tinnitus. ${ }^{6}$

It presents as three syndromes that are, axial neck pain, cervical radiculopathy, and cervical myelopathy. Axial neck pain is the universal presentation due to improper posture and dysfunction in ligamentous or bony elements of the cervical spine. Cervical radiculopathy is due to impingement of intervertebral foramen while cervical myelopathy is due to narrowing of cervical spinal canal. ${ }^{7}$

Loss of lordotic curve also affects the cervical range of motion. ${ }^{8}$ By the age of 60 years, all elderly individuals show spondylotic changes in the radiological investigation. Surgery is not the first choice in asymptomatic elderly patients, and conservative therapeutic strategies should be implemented as the mainstay of treatment. ${ }^{9}$

A study reported that in individuals less than 30 years of age, gender, work hours and same work posture were the associated factors. Housework intensity was responsible in the age group of 30 to 45 years. Walking displayed a protective role and should be considered as a preventive measure of cervical spondylosis. ${ }^{10}$

A recent Japanese study demonstrated an increase in the spinal canal diameter, height, body weight and arm span predicting decreased cases in the future owing to the improved nutritional and environmental factors. ${ }^{11}$ Keeping all these factors in consideration, this study was undertaken to determine the association of cervical spondylosis with respect to neck length, relative neck length and height in our population.

\section{METHODS}

The present study was conducted at the Patel Hospital Karachi, after obtaining ethical approval from Bahria University Medical and Dental College (BUMDC) (Ref. No. ERC 45/2018) and Patel Hospital (Approval No. 57) from September 2018 - February 2019. The subjects were enrolled from orthopedic OPD. It was a case-control study including patients between the ages of 25 and 75 years. Eighty eight diagnosed cases of cervical spondylosis and eighty eight healthy controls were selected using convenient sampling technique from hospital premises. Written informed consent was obtained from both patients and controls. Any patient with cervical tumor, cervical rib, and systemic diseases of bones, thyroid, parathyroid disorders, pregnancy, trauma, and cases with surgery of cervical spine were excluded from the study.

A thorough history and detailed examination of the selected cases and controls was carried out in the orthopedic OPD, followed by a radiograph of cervical spine in the lateral view under supervision of the senior radiologist. The weight and height were also measured with the help of body weight and health scale model no ZT-120. The subject evaluation form was filled by the principal investigator asking the questions related to complaints of neck pain, occupation and usage of electronic devices etc. The participants were asked to stand upright with the neck in neutral position and to depress the shoulders. The neck length was measured by measuring the perpendicular distance between the external occipital protuberance and the tip of the seventh cervical vertebra using a software Synapse (Fujifilm Medical Systems, Tokyo, Japan) (Fig.1). It was cross-checked by the senior radiologist. The relative neck length ${ }^{12}$

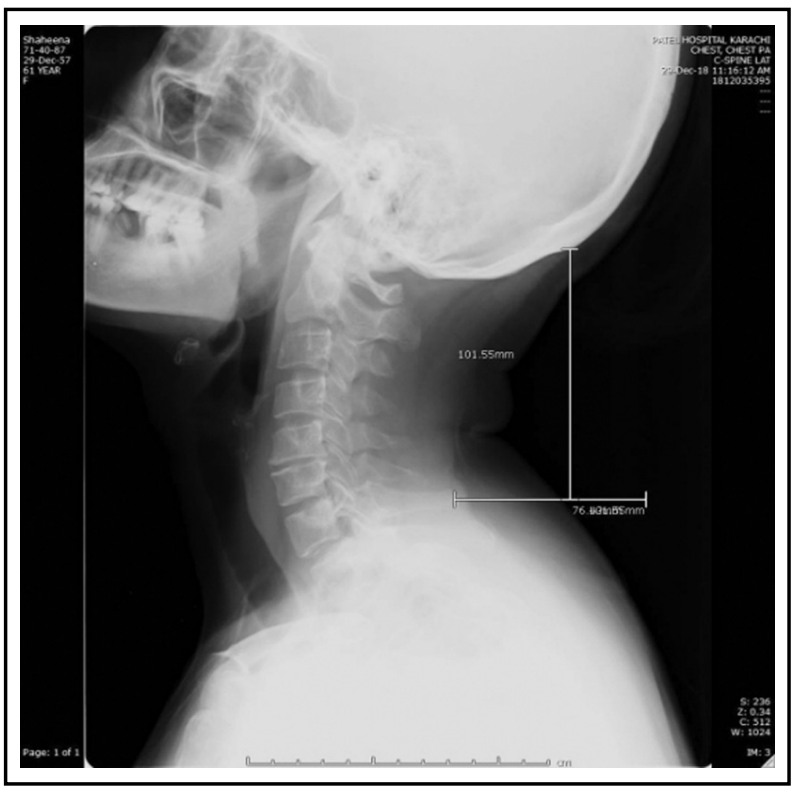

Fig.1: X-ray cervical spine (lateral view) demonstrating radiological parameters for measuring neck length on Synapse. 
was calculated by dividing the neck length with the total height of the individual. The formula is mentioned below:

Relative neck length $=$ absolute neck length $\times 100$

$$
\text { total height of individual }
$$

The Data obtained was entered in the subject evaluation form and analyzed using software SPSS version 23.

\section{RESULTS}

A total of 176 adults (73 males and 103 females) between ages 25 and 75 years participated in the study. The mean neck length in cases and controls was $104.15 \pm 18.9 \mathrm{~mm}$ and $106.98 \pm 19.0$ respectively. The relative neck length in cases and controls was $6.90 \pm 0.89 \mathrm{~mm}$ and $6.93 \pm 0.87 \mathrm{~mm}$ respectively. The mean weight in cases and controls was $69.62 \pm 11.2 \mathrm{~kg}$ and $66.64 \pm 12.44 \mathrm{~kg}$. The height in cases and controls was $163.31 \pm 9.88 \mathrm{~cm}$ and $166.22 \pm 9.07 \mathrm{~cm}$ respectively, with a significant p-Value (Table-I). The mean neck length was significantly shorter in females as compared to males. The height in males was $168.81 \pm 8.42 \mathrm{~cm}$ and in females it was $159.14 \pm 8.88 \mathrm{~cm}$ which was highly significant. The mean weight in females was significantly less as compared to males (Table-II). The comparison between cases and control group was done using Independent T-test and it was found that cases were significantly shorter than controls. The other variables like neck length, relative neck length and weight demonstrated insignificant differences in between cases and controls.

\section{DISCUSSION}

Neck length has been defined as the midline and lateral neck length. A midline neck length (MNL) is the distance between the upper part of the hyoid bone to the jugular notch and lateral neck length (LNL) is the distance from mandibular angle to the middle portion of ipsilateral clavicle. They were measured in relation to the height and correlated with sleep and cardiovascular risk factors. According to a study, men with shorter LNL height ratio were suffering from metabolic syndrome, whereas women with short MNL height ratio were found to be associated with snoring and cardiovascular risk factors. ${ }^{13}$

In another study neck length was defined as cricosternal distance; that is, distance between cricoid cartilage and sternal notch. ${ }^{14}$ Another study tried to standardize the age-dependent interrelationship of neck length with other growth parameters. They measured neck length between inion and C7 spinous process in a neutral position with standing and sitting height in children up to mid-adolescents as percentiles and ratios. These measurements were statistically significant and provided values for quick assessment of short neck in Indian population. ${ }^{12}$

This study is first of its kind in Pakistan, comparing the neck length, relative neck length and total height in relation to cervical spondylosis between cases and controls. It reports the measurements of neck length, relative neck length, and height in our population. It also gives an estimate of the average height in male and female population of Karachi.

Table-I: Comparison of Neck length, relative neck length and height between cases and controls (N=176).

\begin{tabular}{lccc}
\hline Variables & Cases $(N=88)$ Mean \pm S.D & Controls $(N=88)$ Mean \pm S.D & P-value \\
\hline Neck length $(\mathrm{mm})$ & $104.15 \pm 18.9$ & $106.98 \pm 19.0$ & 0.326 \\
Relative neck length $(\mathrm{mm})$ & $6.90 \pm 0.89$ & $6.93 \pm 0.87$ & 0.823 \\
Height $(\mathrm{cm})$ & $163.31 \pm 9.88$ & $166.22 \pm 9.07$ & $0.044^{*}$ \\
Weight $(\mathrm{kg})$ & $69.62 \pm 11.2$ & $66.64 \pm 12.44$ & 0.097 \\
\hline
\end{tabular}

$\mathrm{P}$ value $<0.05$ is considered statistically significant, marked as *, Test applied: Independent T-test.

Table-II: Comparison of Neck length, relative neck length and height within cases between males and females $(\mathrm{N}=88)$.

\begin{tabular}{lccc}
\hline Variables & Male $(\mathrm{N}=38)$ Mean \pm S.D & Female $(\mathrm{N}=50)$ Mean \pm S.D & P-value \\
\hline Neck length $(\mathrm{mm})$ & $109.08 \pm 16.94$ & $100.42 \pm 19.78$ & $0.033^{*}$ \\
Relative neck length $(\mathrm{mm})$ & $7.01 \pm 0.90$ & $6.82 \pm 0.90$ & 0.317 \\
Height $(\mathrm{cm})$ & $168.81 \pm 8.42$ & $159.14 \pm 8.88$ & $0.000^{*}$ \\
Weight $(\mathrm{kg})$ & $73.94 \pm 11.93$ & $66.34 \pm 9.49$ & $0.001^{*}$ \\
\hline
\end{tabular}

P-value $<0.05$ is considered statistically significant, marked as ${ }^{*}$, Test applied: Independent T-test. 
The neck length was measured as the distance from external occipital protuberance to the C7 spinous process. A study reported that cases with cervical spondylosis demonstrated short neck length. ${ }^{15}$ This was in agreement to the present study, where cases showed decreased neck length as compared to controls, although difference was not significant. This finding could be attributed to racial differences. The present study also determined a significant decrease in neck length in females as compared to the males which demonstrated that neck length was directly proportional to the height. The height and weight was significantly higher in the men as compared to the women in another study. ${ }^{16}$

Height is defined as short or tall as the upper and lower limit of normal curve as $3^{\text {rd }}$ and $97^{\text {th }}$ percentile. ${ }^{17}$ In a study, individuals with shorter height displayed protective role against cardiovascular diseases. ${ }^{18}$ Another study explored association of microalbuminuria with height and weight and found out that taller height and lower weight subjects had increased incidence of microalbuminuria. ${ }^{19}$

The present study revealed that incidence of cervical spondylosis was more in short statured subjects. Thus increase in height serves as a protective factor against occurrence of cervical spondylosis. This was supported by a study which demonstrated that cervical spinal canal dimensions had a positive relationship with body height. ${ }^{20}$ Singh et al. (2014) ${ }^{21}$ demonstrated that mean height of group with radiculopathy and myelopathy was $156.58 \pm 8.84 \mathrm{~cm}$, that is shorter than the mean height of control group (159.54 \pm $8.17 \mathrm{~cm}$ ), again emphasizing a protective effect of tall height in cervical spondylosis. This is in accordance to the present study, which showed a mean height of $163.31 \pm 9.88 \mathrm{~cm}$ in cases and $166.22 \pm 9.07 \mathrm{~cm}$ in controls.

In 2016 the Non-Communicable Diseases Risk factor Collaboration NCD-RisC surveyed different countries and reported the tallest height over $182.5 \mathrm{~cm}$ in the Netherlands and shortest in the Guatemala with a height range of $135.8-144.8 \mathrm{~cm} .{ }^{22}$ However, in the present study the tallest height was $176 \mathrm{~cm}$ and shortest was $154 \mathrm{~cm}$. The average height in males was $168.81 \pm 8.42 \mathrm{~cm}$ and in females it was found to be $159.14 \pm 8.88 \mathrm{~cm}$.

\section{CONCLUSION}

According to the present study, individuals with short height were more prone to cervical spondylosis delineating short stature as a risk factor. Short-statured individuals should focus on maintaining a healthy lifestyle, such as exercise, correct work posture, and maintenance of body weight within normal range to prevent cervical spondylosis. The estimate of average height in our population for the risk of cervical spondylosis can also be considered by clinicians to identify patients at risk and implement appropriate measures.

\section{RECOMMENDATIONS}

The study should be done in multiple tertiary care hospitals to correlate other patient variables to identify the risk factors and prevalence of disease in our population.

\section{Grant Support E Financial Disclosures: None.}

\section{REFERENCES}

1. Kolenkiewicz M, Wlodarczyk A, Wojtkiewicz J. Diagnosis and Incidence of Spondylosis and Cervical Disc Disorders in the University Clinical Hospital in Olsztyn, in Years, 2011-2015. Biomed Res Int. 2018;2018:5643839. doi: $10.1155 / 2018 / 5643839$

2. Meng Z, Yu J, Luo C, Liu X, Jiang W, Yu L, et al. Anterior Cervical Spondylosis Surgical Interventions are Associated with Improved Lordosis and Neurological Outcomes at Latest Follow up: A meta-analysis. Sci Rep. 2017;4407:1-9. doi:10.1038/s41598-017-04311-6

3. Kwon Y, Kim JW, Heo JH, Jeon HM, Choi EB, Eom GM, et al. The effect of sitting posture on the loads at cervicothoracic and lumbosacral joints. Technol Health Care. 2018;26(1):409-418. doi: 10.3233/THC-174717

4. Singla D, Veqar Z. Association between forward head, rounded shoulders, and increased thoracic kyphosis: A review of the literature. J Chiropr Med. 2017;16(3):220-229. doi: 10.1016/j.jcm.2017.03.004

5. Sun Z, Yue J, Zhang QH. Electroacupuncture at Jing-jiaji points for neck pain caused by cervical spondylosis: A study protocol for a randomized controlled pilot trial. Trials. 2013;14(1):360. doi: 10.1186/1745-6215-14-360

6. Sun Y, Muheremu A, Tian W. Atypical symptoms in patients with cervical spondylosis: Comparison of the treatment effect of different surgical approaches. Medicine (Baltimore). 2018;97(20):1-4. doi: 10.1097/ MD.0000000000010731

7. Kelly JC, Groarke PJ, Butler JS, Poynton AR, Byrne OJM. The natural history and clinical syndromes of degenerative cervical spondylosis. Adv Orthop. 2012;2012:393642. doi: $10.1155 / 2012 / 393642$

8. Machino M, Yukawa $Y$, Imagama S, Ito K, Katayama $Y$, Matsumoto $\mathrm{T}$, et al. Age-related and degenerative changes in the osseous anatomy, alignment, and range of motion of the cervical spine: A comparative study of radiographic data from 1016 patients with cervical spondylotic myelopathy and 1230 asymptomatic subjects. Spine (Phila Pa 1976). 2016;41(6):476-482. doi: 10.1097/BRS.0000000000001237

9. Wang C, Tian F, Zhou Y, He W, Cai Z. The incidence of cervical spondylosis decreases with aging in the elderly, and increases with aging in the young and adult population: A hospital-based clinical analysis. Clin Interv Aging. 2016;11:47-53. doi: 10.2147/CIA.S93118 
10. Lv Y, Tian W, Chen D, Liu Y, Wang L, Duan F. The prevalence and associated factors of symptomatic cervical Spondylosis in Chinese adults: A community-based crosssectional study. BMC Musculoskelet Disord. 2018;19:325. doi: 10.1186/s12891-018-2234-0

11. Goto SI, Umehara J, Aizawa T, Kokubun S. Comparison of cervical spinal canal diameter between younger and elder generations of Japanese. J Orthop Sci. 2010;15(1):97-103. doi: 10.1007/s00776-009-1427-7

12. Mahajan PV, Bharucha BA. Evaluation of short neck: New neck length percentiles and linear correlations with height and sitting height. Indian Pediatr. 1994;31(10):1193-1203.

13. Han TS, Oh MK, Kim SM, Yang HJ, Lee BS, Park SY, et al. Relationship between neck length, sleep, and cardiovascular risk factors. Korean J Fam Med. 2015;36(1):10-21. doi: 10.4082/ kjfm.2015.36.1.10

14. Tabaee A, Geng E, Lin J, Kakoullis S, Donald MB, Rodriguez $\mathrm{H}$, et al. Impact of neck length on the safety of percutaneous and surgical tracheotomy: A prospective, randomized study. Laryngoscope. 2005;115(9):1685-1690. doi:10.1097/01. MLG.0000175539.25182.2A

15. Taha M, Jafari FH, Kashyar P, Asad MR. Analysis of Neck Length and its Incidence for Cervical Spondylosis in Young Adults. J Rawalpindi Med Coll. 2014;18(1):3-6.

16. Nagata $K$, Yoshimura N, Hashizume H, Muraki S, Ishimoto Y, Yamada H, et al. The prevalence of cervical myelopathy among subjects with narrow cervical spinal canal in a population-based magnetic resonance imaging study: The Wakayama Spine Study. Spine J. 2014;14(12):2811-2817. doi: 10.1016/j.spinee.2014.03.051

17. Bramswig JH. Short and tall stature. Ann Nestle. 2007;65(3):117-127. doi: 10.1159/000112234
18. Samaras TT. Shorter height is related to lower cardiovascular disease risk - A narrative review. Indian Heart J. 2013;65(1):66-71. doi: 10.1016/j.ihj.2012.12.016

19. Cho MH, Kim KS, Chung S. Microalbuminuria Is Associated with Lower Weight and Taller Height in Adolescence. Tohoku J Exp Med. 2017;243(3):151-157. doi: 10.1620/ tjem. 243.151

20. Ulbrich EJ, Schraner C, Boesch C, Hodler J, Busato A Anderson SE, et al. Normative MR cervical spinal canal dimensions. Radiology. 2014;271(1):172-182. doi: 10.1148/ radiol.13120370

21. Singh S, Kumar D, Kumar S. Risk factors in cervical spondylosis. J Clin Orthop Trauma. 2014;5(4):221-226. doi: 10.1016/j.jcot.2014.07.007

22. NCD Risk Factor Collaboration. A century of trends in adult human height. Elife. 2016;5:e13410. doi: 10.7554/ eLife.13410.001

\section{Author's Contribution:}

SBA designed the study, did data collection, compilation and write up of manuscript, is responsible for integrity of research.

AQ did critical review and editing of manuscript. MI helped in data collection and final approval of manuscript.

MFF did statistical analysis. 